\title{
Lobby e Protecionismo no Brasil Contemporâneo*
}

\author{
Thiago Veiga Marzagão
}

Sumário: 1. Introdução; 2. Referencial Teórico; 3. Metodologia; 4. Resultados. 5. Conclusão; A. Apêndice;

Palavras-chave: Política Comercial; Protecionismo; Lobby.

Códigos JEL: F13; F14; D72.

O objetivo deste artigo é explicar por que os diferentes setores da economia brasileira gozam de diferentes níveis de proteção comercial. A hipótese testada é a de que os níveis de proteção são diferentes porque os setores diferem entre si em sua demanda por proteção e em sua capacidade de pressionar o governo a atender essa demanda.

This work attempts to explain why the different industries of Brazilian economy enjoy different degrees of trade protection. The hypothesis under test is that protection degrees vary because industries differ in the amount of protection they demand and in their ability to compel government to meet that demand.

\section{INTRODUÇÃO}

O objetivo deste artigo é explicar por que os diferentes setores da economia brasileira gozam de diferentes níveis de proteção comercial. A hipótese testada é a de que os níveis de proteção são diferentes porque os setores diferem entre si em sua demanda por proteção e em sua capacidade de pressionar o governo a atender essa demanda. O referencial teórico é a Teoria da Proteção Endógena, para a qual a proteção é um bem transacionado entre políticos (ofertantes) e produtores domésticos (demandantes). As variáveis dependentes medem o nível de proteção comercial obtido pelos diferentes setores da economia brasileira em diferentes contextos institucionais. As variáveis independentes medem a demanda por proteção e a capacidade de organização desses setores.

Este artigo compreende cinco seções, sendo esta introdução a primeira. A segunda seção apresenta o referencial teórico utilizado (a Teoria da Proteção Endógena). A terceira seção explica a metodologia utilizada. A quarta seção apresenta e analisa os resultados encontrados. A quinta seção conclui.

\footnotetext{
*O autor agradece Marcelo Resende, editor-associado da RBE, e dois pareceristas anônimos pelas críticas e sugestões referentes à primeira versão do artigo. Todas as opiniões, erros e omissões são, naturalmente, responsabilidade exclusiva do autor.

${ }^{\dagger}$ Ministério da Fazenda. Email: E-mail: thiagomarzagao@gmail.com
} 


\section{REFERENCIAL TEÓRICO}

A chamada Teoria da Proteção Endógena (TPE) consiste em um conjunto de trabalhos que buscam explicar a existência de barreiras comerciais e por que essas barreiras são diferentes entre os vários setores da economia de cada país. Alguns desses trabalhos - como Brock e Magee (1978), Mayer (1984) e Grossman e Helpman (1994) - buscam modelar a relação entre políticos (interessados em apoio político) e produtores domésticos (interessados em proteção). Outros, de natureza empírica - como Caves (1976), Saunders (1980), Ray (1981b,a), Hall et alii (1982), Ray e Marvel (1983, 1984), Trefler (1993), Olarreaga e Soloaga (1998), Grether et alii (1999), Goldberg e Maggi (1999), Gawande e Bandyopadhyay (2000), Gawande et alii (2001), Ehrlich (2005) e Imai et alii (2008) -, buscam, com ou sem o amparo de um modelo teórico específico, testar hipóteses diversas sobre os determinantes do nível de proteção comercial em cada setor da economia. A despeito de todos esses trabalhos serem usualmente considerados como vinculados à TPE, é importante notar que eles carecem de unidade teórica e metodológica: os diferentes modelos teóricos não são compatíveis entre si e os trabalhos de natureza empírica nem sempre derivam de algum modelo teórico pré-existente. ${ }^{1}$

A contribuição mais importante para a TPE no campo teórico é, até o momento, o trabalho de Grossman e Helpman (1994). O modelo desenvolvido por Grossman e Helpman (conhecido como modelo G-H) supõe uma economia pequena e, portanto, incapaz de afetar os preços internacionais. Nessa economia o livre-comércio é a política que maximizaria o bem-estar agregado, de modo que todas as barreiras comerciais resultam da ação de grupos de interesse (lobbies) que representam os diferentes setores da economia. Cada setor faz uso de um fator de produção que lhe é específico e, dessa forma, pode ser prejudicado com o livre-comércio. ${ }^{2}$ Parte desses setores consegue superar seus problemas de ação coletiva e pressionar o governo por proteção comercial. O governo recebe de cada setor organizado uma lista relacionando os diferentes níveis de "apoio político" que o setor está disposto a oferecer em troca dos diferentes níveis de proteção comercial que o governo pode conceder. ${ }^{3} \mathrm{O}$ objetivo do governo é maximizar uma soma ponderada de apoio político e bem-estar econômico geral e, dessa forma, escolherá uma determinada estrutura de proteção e em seguida receberá o apoio político correspondente de cada um dos setores.

O desenvolvimento formal do modelo G-H resulta na proposição de que o nível de proteção de cada setor da economia deriva integralmente das seguintes variáveis: (i) a elasticidade-preço da demanda por importações (quanto maior essa elasticidade, maior o deadweight loss de uma tarifa e menor a proteção concedida); (ii) a capacidade de organização (setores organizados recebem mais proteção que setores não-organizados); e (iii) a razão produção/importações (quanto maior a parcela do consumo nacional abastecida pelos produtores domésticos, mais estes terão a ganhar com a imposição de uma tarifa e maior tende a ser a proteção obtida). Essas proposições sofrem de importantes limitações. Em primeiro lugar, as proposições (i) e (iii) podem ser facilmente revertidas. Quanto maior a elasticidade-preço da demanda por importações, maior o deadweight loss associado mas, também, maior o ganho para o setor protegido; e quanto maior a razão produção/importações, maior o ganho para o setor protegido mas, também, maior o deadweight loss associado. Em ambos os casos, portanto, a relação de causa-e-efeito é ambígua. Quanto à proposição (ii), o nível de organização de cada setor da economia é mais bem descrito como uma variável contínua e não binária. Tento em vista tais limitações, o presente trabalho será de natureza exploratória, ${ }^{4}$ não partindo de algum modelo teórico pré-existente.

\footnotetext{
${ }^{1}$ Um survey das principais abordagens metodológicas da TPE é realizado em Gawande e Krishna (2003).

${ }^{2}$ Se os fatores não fossem específicos não haveria custos em migrá-los de um setor para outro e as barreiras comerciais não trariam qualquer benefício aos setores protegidos.

${ }^{3}$ O modelo G-H não especifica um tipo exato de "apoio político" - que pode ser, por exemplo, contribuições de campanha.

${ }^{4}$ A exemplo de trabalhos como Olarreaga e Soloaga (1998), Grether et alii (1999) e Ehrlich (2005).
} 
Lobby e Protecionismo no Brasil Contemporâneo

\section{METODOLOGIA}

Foram construídas oito variáveis dependentes, as quais representam o nível de proteção obtido por cada setor da economia brasileira em três contextos institucionais distintos: a formulação da Tarifa Externa Comum do Mercosul (TEC), a formulação da Lista de Exceções do Brasil à TEC e a formulação das ofertas de abertura comercial apresentadas pelo Mercosul na negociação da Área de Livre-Comércio das Américas (ALCA) e na negociação com a União Européia. Cada variável dependente foi regredida a quatro variáveis explanatórias que (acredita-se) influenciam a demanda por proteção de cada setor e/ou a capacidade de cada setor de pressionar o governo a atender essa demanda. A unidade de observação adotada são os grupos de atividade econômica compreendidos na Seção D ("Indústria de Transformação") da Classificação Nacional de Atividades Econômicas (CNAE), excluídos os grupos referentes à prestação de serviços ou para os quais não havia dados disponíveis. Como o nível de proteção comercial só está disponível em termos de produtos (e não de setores), utilizou-se tabela de correlação do IBGE $^{5}$ para correlacionar os 9.714 produtos que constam da Nomenclatura Comum do Mercosul (NCM) ${ }^{6}$ com os 104 grupos de atividade econômica da Seção D da CNAE.?

Todas as quatro variáveis explanatórias são contínuas. Das oito variáveis dependentes, seis são contínuas e duas são binárias. As seis variáveis contínuas são porcentagens ou médias calculadas a partir de dados individuais. Nesses casos, utilizou-se o método dos mínimos quadrados ponderados, adotando-se o número de observações individuais como peso. ${ }^{8}$ Para as duas variáveis binárias, adotou-se o modelo logístico. Em todos os modelos optou-se pela utilização de erros-padrão robustos à heterocedasticidade (variante HC3 nos casos em que a variável dependente é contínua). As análises gráficas não sugeriram quaisquer relações não-lineares (quadráticas, exponenciais, etc.) entre as variáveis, de modo que estas foram utilizadas em seus formatos originais, sem transformações. Os outliers foram identificados mas não removidos: em nenhum caso a discrepância pareceu derivar de erros de medição e, portanto, a exclusão dessas observações poderia privar o modelo de informações importantes. Nos seis casos de variável dependente contínua, os valores mínimo e máximo que essa variável pode atingir são conhecidos (por exemplo, a tarifa média situa-se necessariamente entre 0 e 35), o que sugeriu inicialmente a utilização de um modelo tobit duplo-censurado. Não obstante, os resultados com o modelo tobit e com o modelo dos mínimos quadrados ponderados foram essencialmente os mesmos, de modo que se optou por reportar apenas os resultados com esse segundo método. Em cada regressão calculou-se o fator de inflação da variância para os respectivos regressores; em todos os casos essa estatística variou entre 1,0 e 2,0, o que sugere não haver problemas de multicolinearidade. ${ }^{9}$ Por fim, foram incluídos termos multiplicativos com o objetivo de identificar eventuais interações entre as variáveis explanatórias; em nenhum caso a inclusão desses termos melhorou o modelo.

\footnotetext{
${ }^{5}$ Disponível em http://www.ibge.gov.br/concla/cnae/correspondencias/NCM2002XCNAE.xls. Acesso em: 12 mai 2008.

${ }^{6}$ Excluídos os produtos que guardam correspondência com múltiplos grupos de atividade econômica da CNAE ou com nenhum deles.

${ }^{7}$ Excluídos os grupos referentes a prestação de serviços ou para os quais não havia dados disponíveis.

${ }^{8} \mathrm{~A}$ justificativa para a escolha desse método é que as observações calculadas a partir de numerosos dados individuais são mais consistentes. Essa escolha é corroborada empiricamente: para cada variável dependente contínua, realizou-se uma regressão pelo método dos mínimos quadrados ordinários e outra pelo método dos mínimos quadrados ponderados. Em todos os casos os resultados foram substancialmente melhores com o método dos mínimos quadrados ponderados. Portanto, apenas estes últimos serão reportados.

${ }^{9}$ Conforme Mendenhall e Sicinch (2003), na presença de multicolinearidade os erros-padrão das estimativas são inflados. 0 fator de inflação da variância é calculado como $1 /\left(1-R_{i}^{2}\right)$, onde $R_{i}^{2}$ é a estatística $R^{2}$ resultante da regressão da variável independente i a todas as demais variáveis independentes do modelo. Conforme Gujarati (2006), um fator de inflação da variância inferior a 10 sugere não haver problemas de multicolinearidade.
} 


\subsection{Construção das Variáveis Dependentes}

(a) TEC5 é a média tarifária nominal de cada setor em 2005. Uma medida alternativa, mais refinada, seria o grau de proteção efetiva. ${ }^{10}$ Ocorre, porém, que a última Matriz de Insumo-Produto (MIP) do IBGE é de 1996 e seria temerário assumir que os coeficientes técnicos que representam as relações intersetoriais de consumo se mantêm os mesmos desde então (uma comparação entre a MIP-1985 e a MIP-1996 revela diferenças substanciais entre os coeficientes técnicos de cada setor). Ademais, o nível de agregação da MIP (64 setores) ${ }^{11}$ é maior que o da CNAE (95 setores na Seção D), ${ }^{12}$ o que resultaria em perda de informação (como o lobby acontece no nível de cada tarifa individualmente, quanto maior o nível de agregação, menor a precisão da análise). Outra possibilidade seria ponderar cada tarifa pelas respectivas importações (o que, em tese, levaria em consideração a relevância de cada produto para o setor), mas isso subestimaria a proteção dos produtos com tarifa proibitiva (cujas importações são zero) e superestimaria a proteção dos produtos com tarifa baixa (que tendem a ter mais importações).

(b) LIST assume valor 1 se, no primeiro semestre de 2005, algum produto (a oito dígitos da NCM) do setor estava incluído na Lista de Exceções do Brasil à TEC com alíquota a maior e 0 em caso contrário. A Lista de Exceções do Brasil à TEC é um mecanismo por meio do qual o Brasil pode estabelecer unilateralmente (i.e., sem consulta ao Mercosul) as tarifas de até 100 produtos. Essas tarifas podem diferir da TEC para mais ou para menos e, a cada seis meses, até $20 \%$ dos produtos constantes da Lista podem ser substituídos. As tarifas estabelecidas na Lista só valem para as importações brasileiras (os demais países-membros do Mercosul podem aplicar a TEC ou incluir o mesmo produto em suas respectivas Listas de Exceções). Ao todo, LIST assumiu valor 1 para oito setores e valor 0 para 85 setores.

(c) ALC1 é a porcentagem de produtos (a oito dígitos da NCM) de cada setor que foram excluídos da oferta de liberalização apresentada pelo Mercosul na negociação da ALCA, em 2003. Nessa oferta, os 9.621 produtos que compunham a TEC vigente à época foram distribuídos entre quatro "cestas" de desgravação tarifária, a saber: Cesta A (desgravação imediata), Cesta B (desgravação em até cinco anos), Cesta C (desgravação em até dez anos) e Cesta D (desgravação em prazo indefinido, superior a dez anos). A oferta compreendeu $100 \%$ dos produtos, os quais foram distribuídos da seguinte forma: $17,44 \%$ dos produtos foram alocados na Cesta A, 4,79\% na Cesta B, 29,35\% na Cesta C e $48,39 \%$ na Cesta D. Como a Cesta D não estabelecia qualquer prazo de desgravação, na prática os produtos ali alocados estavam excluídos da oferta. Portanto, ALC1 representa o percentual de produtos de cada setor que foram alocados na Cesta D.

(d) ALC2 é o tempo médio, em anos, até a desgravação total dos produtos (a oito dígitos da NCM) de cada setor incluídos na oferta do Mercosul na ALCA, em 2003. Por exemplo, o setor "Fabricação de produtos farmacêuticos" (grupo de atividade econômica $n^{\circ} 245$ da CNAE), ao qual correspondem 673 produtos na TEC, teve 257 produtos alocados na Cesta A, 10 na Cesta B, 124 na Cesta C e 282 na Cesta D. Dessa forma, o tempo médio de desgravação dos produtos do setor efetivamente incluídos na oferta era de aproximadamente 3,95 anos. Nesse cálculo, atribuiu-se (algo arbitrariamente) o valor de um ano à Cesta $\mathrm{A}$ (desgravação imediata) e foram desconsiderados os produtos incluídos na Cesta D (cujo prazo de desgravação era indefinido).

\footnotetext{
${ }^{10} \mathrm{O}$ conceito de tarifa efetiva leva em consideração a tarifa nominal do produto ponderada pela tarifa nominal de seus insumos (Balassa, 1971, p. 3-25). A idéia subjacente é que, ao encarecer-se a importação dos insumos, na verdade se está desprotegendo o bem final. Algebricamente, a tarifa efetiva é expressa como $\left(V_{t}-V_{w}\right) / V_{w}$, onde $V_{w}$ é o valor agregado a preços internacionais e $V_{t}$ é o valor agregado sob proteção.

${ }^{11}$ Total de 80 setores, sendo 16 deles não-comercializáveis (serviços).

${ }^{12}$ Total de 104 setores, sendo nove deles não-comercializáveis (serviços).
} 
É fácil perceber que as variáveis ALC1 e ALC2 são de certa forma complementares. ALC1 desconsidera a distribuição dos produtos de cada setor entre as diferentes cestas, o que é um problema na medida em que dois setores com igual porcentual de produtos incluídos podem diferir bastante quanto à alocação desses produtos. ALC2, por seu turno, desconsidera a porcentagem de produtos incluídos na oferta: dois setores cujos produtos incluídos tenham sido distribuídos igualmente entre as cestas A, B e C podem diferir bastante quanto à razão $\mathrm{n}^{\circ}$ de produtos incluídos $/ \mathrm{n}^{\circ}$ de produtos compreendidos na TEC.

(e) UE1A é a porcentagem de produtos (a oito dígitos da NCM) de cada setor que foram excluídos da oferta inicial de liberalização apresentada pelo Mercosul na negociação com a União Européia, em 2001. À semelhança da negociação na ALCA, os produtos foram distribuídos entre diferentes cestas de desgravação. Essas cestas, porém, eram de natureza distinta das negociadas na ALCA porque previam não apenas um prazo para a eliminação total das tarifas (100\% de preferência) mas, também, cronogramas de redução tarifária progressiva até a desgravação total:

Tabela 1 - Cestas Utilizadas na Oferta Inicial do Mercosul à União Européia (2001)

\begin{tabular}{|c|c|c|c|c|c|c|c|c|c|c|c|}
\hline & \multicolumn{11}{|c|}{ Cronograma de Redução Tarifária (margens de preferência ano a ano, por cesta) } \\
\hline & Ano 0 & Ano 1 & Ano 2 & Ano 3 & Ano 4 & Ano 5 & Ano 6 & Ano 7 & Ano 8 & Ano 9 & Ano 10 \\
\hline A & $100 \%$ & & & & & & & & & & \\
\hline B & & $50 \%$ & $50 \%$ & $50 \%$ & $50 \%$ & $50 \%$ & $50 \%$ & $50 \%$ & $50 \%$ & $100 \%$ & \\
\hline C & & & $10 \%$ & $10 \%$ & $20 \%$ & $30 \%$ & $50 \%$ & $60 \%$ & $70 \%$ & $90 \%$ & $100 \%$ \\
\hline $\mathrm{D}$ & & & $10 \%$ & $10 \%$ & $10 \%$ & $20 \%$ & $40 \%$ & $50 \%$ & $60 \%$ & $80 \%$ & $100 \%$ \\
\hline $\mathrm{E}$ & & & $10 \%$ & $10 \%$ & $10 \%$ & $10 \%$ & $20 \%$ & $30 \%$ & $50 \%$ & $70 \%$ & $100 \%$ \\
\hline
\end{tabular}

Fonte: Ministério do Desenvolvimento, Indústria e Comércio Exterior.

Dos 9.410 itens que então compunham a NCM, o Mercosul incluiu em sua oferta apenas 3.691 (ou seja, $40 \%$ do total), os quais respondiam por $32 \%$ de tudo que o bloco importava da União Européia. ${ }^{13}$ Daqueles 3.691 itens, $14,92 \%$ foram alocados na Cesta A, 30,04\% na Cesta B, $16,52 \%$ na Cesta C, 35,35\% na Cesta D e 3,14\% na Cesta E. Os 5.719 itens restantes (quase todos referentes a bens industriais) foram considerados sensíveis demais mesmo para a cesta de prazo mais longo e, por essa razão, ficaram de fora da oferta. ${ }^{14}$

(f) UE1B assume valor 1 para os setores integralmente excluídos da oferta do Mercosul à União Européia em 2001 e 0 para os demais setores. Como aproximadamente $30 \%$ dos setores foram integralmente excluídos da oferta, não foi possível calcular uma variável análoga a ALC2 (no cálculo das médias, o denominador seria zero em todos esses casos).

(g) UE4A é a porcentagem de produtos (a oito dígitos da NCM) de cada setor que foram excluídos da oferta final de liberalização apresentada pelo Mercosul na negociação com a União Européia, em $2004 .{ }^{15}$ Foram considerados excluídos os produtos classificados como "sensíveis" e os produtos para os quais foram oferecidas preferências fixas no lugar de cronogramas de desgravação.

A oferta final do Mercosul incluiu 91,5\% do universo tarifário. O prazo de desgravação de cada cesta foi alterado e a alocação de itens entre as cestas também. Para o setor automotivo, de grande interesse para a UE, criou-se uma cesta adicional (Cesta F), cuja desgravação teria início apenas no oitavo ano e término no $17^{\circ}$ ano. Para 185 itens foram oferecidas, no lugar da alocação em cestas, preferências fixas de $20 \%$ ou $50 \%$ (dependendo do caso). A alocação dos 8.909 itens incluídos na oferta foi a seguinte: $13,11 \%$ na Cesta A, $19,76 \%$ na Cesta B, $12,09 \%$ na Cesta C, $21,2 \%$ na Cesta D, 31,25\% na Cesta E, 0,51\%

\footnotetext{
${ }^{13}$ A título de comparação, a oferta da União Européia compreendeu $89 \%$ dos itens da Nomenclatura Combinada daquele bloco e $90 \%$ de tudo que o bloco importava do Mercosul.

${ }^{14} \mathrm{~A}$ porcentagem de itens excluídos, por setor da economia, é informada no Apêndice.

${ }^{15} \mathrm{~A}$ íntegra da oferta está disponível em http://www.comercio.gov.ar/dnpce/negociaciones/ue.html. Acesso em: 18 jul. 2008
} 
na Cesta F e 2,08\% receberam preferências fixas (de $20 \%$ ou 50\%). A Tabela 2 ,apresenta as cestas utilizadas na oferta do Mercosul em 2004:

Tabela 2 - Cestas Utilizadas na Última Oferta do Mercosul à União Européia (2004)

\begin{tabular}{|c|c|c|c|c|c|c|c|c|c|c|c|}
\hline & \multicolumn{11}{|c|}{ Cronograma de redução tarifária (margens de preferência ano a ano, por cesta) } \\
\hline & Ano 0 & Ano 1 & Ano 2 & Ano 3 & Ano 4 & Ano 5 & Ano 6 & Ano 7 & Ano 8 & Ano 9 & Ano 10 \\
\hline A & $100 \%$ & & & & & & & & & & \\
\hline B & $50 \%$ & $50 \%$ & $100 \%$ & & & & & & & & \\
\hline C & $11 \%$ & $22 \%$ & $33 \%$ & $44 \%$ & $55 \%$ & $66 \%$ & $77 \%$ & $88 \%$ & $100 \%$ & & \\
\hline D & & $10 \%$ & $15 \%$ & $25 \%$ & $30 \%$ & $40 \%$ & $50 \%$ & $60 \%$ & $70 \%$ & $85 \%$ & $100 \%$ \\
\hline$E$ & & & $10 \%$ & $15 \%$ & $25 \%$ & $35 \%$ & $45 \%$ & $55 \%$ & $70 \%$ & $85 \%$ & $100 \%$ \\
\hline & & & & & & sta F & & & & & \\
\hline & Ano 8 & Ano 9 & Ano 10 & Ano 11 & Ano 12 & Ano 13 & Ano 14 & Ano 15 & Ano 16 & Ano 17 & \\
\hline & $10 \%$ & $20 \%$ & $30 \%$ & $40 \%$ & $50 \%$ & $60 \%$ & $70 \%$ & $80 \%$ & $90 \%$ & $100 \%$ & \\
\hline
\end{tabular}

(h) UE4B é o tempo médio, em anos, até a desgravação total dos produtos (a oito dígitos da NCM) de cada setor incluídos na oferta final do Mercosul à União Européia, em 2004. A forma de cálculo é a mesma adotada na construção de ALC2, explicada acima. Portanto, considerou-se apenas o prazo de desgravação total, não se levando em consideração os cronogramas de redução tarifária progressiva. Por exemplo, o setor "Fabricação de produtos químicos inorgânicos" (grupo de atividade econômica $\mathrm{n}^{0} 241$ da CNAE), ao qual correspondem 447 produtos na TEC, teve 20 produtos alocados na Cesta A, 206 na Cesta B, 159 na Cesta C, 12 na Cesta D e 34 na Cesta E. Atribuindo-se o valor 1 à Cesta $\mathrm{A}$ (desgravação imediata), o tempo médio de desgravação total dos produtos do setor incluídos na oferta era de aproximadamente 5,02 anos.

\subsection{Construção das Variáveis Independentes}

A literatura da TPE oferece uma ampla gama de variáveis explanatórias. Grosso modo, essas variáveis podem ser categorizadas da seguinte forma (por conveniência, a expressão ceteris paribus será omitida):

- Indicadores de competitividade. Quanto menos competitivo um setor, maior sua dependência da proteção comercial para sobreviver e maior a demanda por proteção.

- Indicadores da especificidade dos fatores. Quanto mais específicos os fatores utilizados por determinado setor, mais dificil será a migração desses fatores para outras atividades e maior a demanda por proteção.

- Grau de organização relativa. Quanto mais organizado um setor, vis-à-vis seus consumidores, menores seus custos de ação coletiva e maior a demanda por proteção.

- Transferências adicionais. Quanto mais recursos empregados na obtenção de outras medidas redistributivas, menos recursos disponíveis para empregar na obtenção de proteção comercial e menor a demanda por proteção.

A operacionalização dessas variáveis não é simples. As variáveis dependentes (detalhadas em 3.1, acima) referem-se, quase todas, a políticas comuns do Mercosul (a única exceção é LIST). O ideal, portanto, seria calcular cada variável explanatória quatro vezes - uma para cada país do bloco. A especificação resultante conteria 16 variáveis. Essa alternativa, porém, esbarra nos problemas de comparabilidade e disponibilidade de dados que inevitavelmente surgem quando se inclui mais de um país na análise. Nem sempre as mesmas estatísticas estão disponíveis para todos os países. Quando estão, freqüentemente a forma de cálculo é diferente. E quando a fórmula de cálculo é a mesma, o sistema 
de classificação de setores é distinto, não havendo correlação clara com a CNAE. Uma alternativa seria recorrer ao banco de dados da Organização das Nações Unidas para o Desenvolvimento Industrial (UNIDO), que reúne estatísticas industriais uniformizadas de diversos países e é a fonte utilizada por Olarreaga e Soloaga (1998). Todavia, apenas duas das quatro variáveis explanatórias construídas neste trabalho estão contempladas naquela base de dados ou podem ser calculadas a partir daquela fonte. Ademais, os resultados reportados no próprio trabalho de Olarreaga e Soloaga (1998) sugerem que o peso do Brasil no Mercosul é suficiente para desconsiderar os demais países. Por essas razões, apenas variáveis explanatórias referentes ao caso brasileiro foram incluídas na análise.

Outro problema encontrado foi a inexistência de estatísticas quanto à especificidade dos fatores de produção. Cogitou-se utilizar como proxy a idade média das empresas, mas essa estatística só está disponível em nível de agregação superior ao utilizado e, de todo modo, seria uma proxy bastante imprecisa.

Também não foi possível considerar as demais transferências recebidas por cada setor. Essas transferências nem sempre são quantitativas: podem ser, por exemplo, regulamentos limitando a entrada de novos competidores no mercado. A inclusão apenas de variáveis quantitativas (como crédito oficial, isenções fiscais, etc.) poderia resultar em sinais diferentes do esperado: a hipótese que se quer testar é que a proteção diminui conforme aumenta o total das demais transferências recebidas (dado que a capacidade de cada setor pressionar o governo é finita). Incluir no modelo apenas algumas das muitas transferências poderia resultar em correlações positivas espúrias.

Por fim, não foi possível trabalhar com dados referentes ao grau de organização dos consumidores. Setores cujos consumidores são organizados enfrentam contra-lobby e tendem a receber menos proteção. Fornecedores de autopeças, por exemplo, têm dificuldade em obter proteção porque enfrentam o contra-lobby de grandes montadoras, fortemente organizadas e com grande capacidade de influenciar o governo. Já as montadoras têm mais capacidade de obter proteção porque seus consumidores são milhões de indivíduos dispersos e individualmente irrelevantes na formulação da política comercial. Pensou-se, inicialmente, em construir uma variável dummy para diferenciar entre produtores de bens intermediários e produtores de bens finais. O problema é que, no nível de agregação utilizado, os setores estão definidos de forma muito ampla e compreendem, quase todos, tanto produtores de bens intermediários quanto produtores de bens finais.

Em face das razões acima, as variáveis explanatórias adotadas neste trabalho dizem respeito apenas à competitividade e ao grau de organização dos diferentes setores produtivos da economia brasileira. Ao todo, foram utilizadas quatro variáveis explanatórias, sendo duas referentes à competitividade (TRAB e INST) e duas referentes ao grau de organização (FIRM e CONC):

(a) FIRM é o número de firmas de cada setor dividido por mil, conforme dados da Pesquisa Industrial Anual por Empresas (PIA-Empresas) do IBGE. A idéia é que quanto maior o grupo interessado em determinado bem público, maiores os custos de organização e menor a fração do benefício que será auferida por cada membro do grupo individualmente (Olson, 1971, p. 48). Pode-se esperar, portanto, que a quantidade de firmas esteja inversamente relacionada ao nível de proteção comercial.

(b) CONC é o grau de concentração econômica de cada setor, expresso como [(número de trabalhadores alocados nas quatro maiores empresas do setor / número total de trabalhadores do setor) $x$ 100], conforme dados do Cadastro Central de Empresas (CEMPRE) do IBGE. Em grupos heterogêneos determinados integrantes podem ter tanto interesse na obtenção de um bem público a ponto de arcarem sozinhos com os custos dessa obtenção (Olson, 1971, p. 34). Dessa forma, setores cuja produção esteja concentrada nas mãos de poucas firmas tendem a obter mais proteção do que setores cuja produção esteja distribuída de forma mais eqüitativa entre as firmas existentes. Espera-se, portanto, uma correlação positiva entre CONC e as variáveis dependentes. 
Não há dados de concentração disponíveis para períodos anteriores a 2002. Portanto, nos casos de UE1A e UE1B (cujo ano-base é 2001) substituiu-se CONC por ESCL, que é a escala média das firmas de cada setor (a idéia é que setores mais concentrados são caracterizados por firmas de maior escala). ESCL é calculada como o valor da produção industrial bruta (em mil $\mathrm{R} \$$ ) dividido por FIRM e multiplicado por mil, conforme dados da PIA-Empresa.

(c) TRAB é a trabalho-intensividade de cada setor, medida como a razão (vezes 100) entre "salários e outras remunerações pagas (em mil $\mathrm{R} \$$ ) ao pessoal assalariado ligado diretamente à produção de cada setor" e o valor da transformação industrial (em mil R\$) de cada setor, conforme dados da PIA-Empresa. O Brasil, sendo abundante em mão-de-obra, é mais competitivo nos setores mais trabalho-intensivos, que por sua vez demandarão menos proteção. Logo, espera-se uma correlação negativa entre TRAB e as variáveis dependentes.

(d) INST é a porcentagem de trabalhadores de cada setor com curso superior completo, conforme dados da Relação Anual de Informações Sociais (RAIS) do Ministério do Trabalho e Emprego. O Brasil é escasso em mão-de-obra qualificada e, portanto, os setores intensivos nesse fator de produção tendem a ser menos competitivos e a demandar mais proteção. Portanto, espera-se uma correlação positiva entre INST e as variáveis dependentes.

Em cada regressão as variáveis independentes são calculadas para o ano anterior ao ano-base da variável dependente. Por exemplo, o ano-base de ALC1 é 2003 porque foi naquele ano que o Mercosul apresentou sua oferta de liberalização na ALCA. Logo, os valores de FIRM, CONC, TRAB e INST utilizados na regressão com ALC1 se referem ao ano 2003-1=2002. Há duas razões para o uso dessa defasagem temporal. A primeira é que quando um setor pressiona o governo por proteção a resposta raramente é imediata: a pressão exercida no ponto $t_{0}$ da linha de tempo provavelmente só resultará na implementação de uma política redistributiva no ponto $t_{1}$. A segunda razão é que a estrutura de mercado de cada setor (número de firmas, grau de concentração, etc.) pode ser (ainda que de forma pouca significativa) afetada pela estrutura de proteção vigente. Porém, como o futuro não pode causar o passado (Gujarati, p. 560), a defasagem minimiza esse problema: a estrutura de proteção vigente em 2003 não pode ter afetado a estrutura de mercado de 2002. Uma alternativa seria substituir o método dos mínimos quadrados ponderados pelo método dos mínimos quadrados em dois estágios. Entretanto, não foram encontradas variáveis instrumentais consistentes (i.e., fortemente correlacionadas com o regressor e sem correlação substantiva com o regressando) que pudessem ser utilizadas no primeiro estágio. ${ }^{16}$

\section{RESULTADOS}

As Tabelas 3 e 4,apresentam os resultados das regressões. O número entre parênteses, abaixo de cada coeficiente, é a estatística $p$ resultante de cada teste $t$ (Tabela 3) ou $z$ (Tabela 4). Os asteriscos indicam a significância estatística: $90 \%\left({ }^{*}\right), 95 \%\left(^{(*)}\right)$ ou $99 \%\left(^{(* *}\right)$. Para cada variável dependente reportase também o $R^{2}$ ajustado (Tabela 3) ou o pseudo- $\mathrm{R}^{2}$ de McFadden (Tabela 4), o número de observações $(n)$, a estatística $\mathrm{F}$ (Tabela 3) ou Wald-chi ${ }^{2}$ (Tabela 4) e, abaixo desta e entre parênteses, a respectiva significância estatística. Os coeficientes da Tabela 3 estão em unidades de desvio-padrão, para facilitar a comparação entre os diferentes regressores.

\footnotetext{
${ }^{16}$ Os trabalhos que utilizam regressões em dois estágios freqüentemente adotam variáveis instrumentais inconsistentes. Um exemplo é Saunders (1980), que inclui entre seus regressores a intensidade exportadora (como proxy de competitividade). Como a estrutura de proteção vigente pode afetar a pauta exportadora do país (por exemplo, estimulando o atendimento do mercado doméstico em detrimento do mercado internacional), Saunders utiliza o método dos mínimos quadrados em dois estágios e toma como variável instrumental (dentre outras) a trabalho-intensividade de cada setor. O problema é que a competitividade de cada setor deriva, em essência, da utilização mais ou menos intensiva dos diferentes fatores de produção - portanto, a trabalhointensividade pode ser considerada, ela própria, uma variável explanatória (de fato, é uma das quatro variáveis explanatórias utilizadas no presente trabalho, como se verá adiante).
} 
Lobby e Protecionismo no Brasil Contemporâneo

Tabela 3 - Resultados das Regressões com Variáveis Dependentes Contínuas

\begin{tabular}{|c|c|c|c|c|c|c|c|}
\hline & FIRM & CONC & TRAB & INST & $\mathrm{R}^{2}$ ajust. & $n$ & $F$ \\
\hline TEC5 & 0,064786 & 0,220899 & 0,497768 & $-0,36305$ & 0,5683 & 93 & 19,32 \\
& $(0,335)$ & $(0,036)^{* *}$ & $(0)^{* * *}$ & $(0,013)^{* *}$ & & & $(0)$ \\
\hline ALC1 & 0,214108 & 0,259008 & 0,12269 & $-0,31225$ & 0,2109 & 93 & 4,90 \\
& $(0,142)$ & $(0,037)^{* *}$ & $(0,507)$ & $(0,076)^{*}$ & & & $-0,0013$ \\
\hline ALC2 & $-0,00118$ & 0,207203 & 0,198659 & $-0,59936$ & 0,4645 & 85 & 8,91 \\
& $(0,984)$ & $(0,131)$ & $(0,17)$ & $(0,002)^{* * *}$ & & & $(0)$ \\
\hline UE1A & 0,110019 & 0,299581 & $-0,21979$ & $-0,77819$ & 0,4616 & 93 & 13,42 \\
& $(0,304)$ & $(0)^{* * *}$ & $(0,234)$ & $(0)^{* * *}$ & & & $(0)$ \\
\hline UE4A & 0,476298 & 0,170968 & 0,048152 & $-0,06125$ & 0,2003 & 92 & 10,51 \\
& $(0)^{* * *}$ & $(0,101)$ & $(0,755)$ & $(0,724)$ & & & $(0)$ \\
\hline UE4B & $-0,13488$ & 0,152466 & 0,556948 & $-0,28084$ & 0,4677 & 92 & 11,86 \\
& $(0,201)$ & $(0,301)$ & $(0,001)^{* * *}$ & $(0,115)$ & & & $(0)$ \\
\hline
\end{tabular}

Tabela 4 - Resultados das Regressões com Variáveis Dependentes Binárias

\begin{tabular}{rl|c|c|c|c|c|c|c|}
\hline & FIRM & CONC & TRAB & INST & pseudo-R & $n$ & Wald chi $^{2}$ \\
\hline LIST & $-0,0206054$ & $-0,0027955$ & $-0,0990716$ & $-0,2169039$ & 0,0996 & 93 & 6,29 \\
& $(0,847)$ & $(0,927)$ & $(0,256)$ & $(0,024)^{* *}$ & & & $(0,1787)$ \\
\hline UEIB & $-0,01992$ & 0,003686 & $-0,00757$ & $-0,23249$ & 0,1526 & 93 & 8,86 \\
& $(0,844)$ & $(0,051)^{*}$ & $(0,854)$ & $(0,005)^{* * *}$ & & & $(0,0646)$ \\
\hline
\end{tabular}

Como se nota, a variável INST é a única que mantém o mesmo sinal em todas as regressões. Também é a variável que com maior freqüência aparece como significativa: em seis dos oito modelos. Essa consistência de sinais e significância sugere que, do conjunto de regressores utilizados neste trabalho, INST é a variável mais importante e deveria ser incluída em trabalhos futuros que pretendam estudar o protecionismo brasileiro a partir de uma abordagem econométrica. Por outro lado, a correlação esperada entre INST e as variáveis dependentes era positiva. O sinal negativo pode ser interpretado de duas formas: (i) a premissa de que o Brasil é escasso em mão-de-obra qualificada é falsa e, dessa forma, setores com mão-de-obra mais instruída são mais competitivos e demandam menos proteção; ou (ii) a relação entre qualificação da mão-de-obra e proteção comercial é regida por outros fatores que não a competitividade. Dado ser improvável que o Brasil seja um país abundante em mão-de-obra qualificada, a segunda explicação parece mais plausível. Considerando que o salário é proporcional ao grau de instrução, ${ }^{17}$ o governo pode simplesmente estar disposto a conceder mais proteção àqueles trabalhadores com menores salários - independente de sua competitividade. A relação entre INST e nível de proteção seria, portanto, mediada por motivações sociais que, via de regra, são negligenciadas nos trabalhos da TPE. Essa explicação - se correta - reforça o argumento de Nordlinger (1981) quanto à capacidade de o Estado atuar de forma autônoma. O sinal negativo de INST também lança dúvidas quanto à interpretação de resultados semelhantes em outros trabalhos. Ray (1981a), por exemplo, também encontra uma correlação negativa e significativa entre qualificação da mão-de-obra e proteção comercial nos EUA. Ele explica essa correlação assumindo que os EUA são abundantes em mão-de-obra qualificada e que, portanto, os setores com trabalhadores menos instruídos são menos competitivos e demandam mais proteção. Entretanto, se essa correlação também é negativa num país como o Brasil - escasso em mãode-obra qualificada - é possível que o resultado encontrado por Ray também se explique, ao menos em parte, por motivações sociais.

Depois de INST, a variável que apresentou maior consistência de sinal e significância foi CONC. 0 sinal de CONC foi positivo em sete dos oito modelos e, desses sete, em quatro houve significância estatística. 0 sinal positivo era o esperado e corrobora a hipótese de que, em setores mais concentrados, as maiores empresas dispõem-se a arcar com parcela relevante do lobby protecionista.

${ }^{17} \mathrm{O}$ coeficiente de correlação linear entre INST e o salário médio em cada setor (calculado a partir de dados da PIA-Empresa 2004) é de $78,85 \%$. 
TRAB apresentou sinal positivo em cinco dos oito modelos e, desses cinco, em dois o coeficiente foi estatisticamente significativo. Esse sinal positivo é oposto ao que se esperava e pode ser interpretado de diferentes formas: (i) o Brasil é um país relativamente abundante em capital; ou (ii) a relação entre trabalho-intensividade e proteção não se dá em termos de competitividade, sendo mediada por outros fatores. Esta segunda hipótese não se sustenta empiricamente. Em princípio, quanto mais trabalhointensivo um setor, maior o número de trabalhadores - e portanto de eleitores - afetados negativamente pela competição externa. Entretanto, se a preocupação do governo fosse com a quantidade de eleitores, os setores mais protegidos seriam aqueles com o maior número absoluto de trabalhadores e não necessariamente aqueles mais trabalho-intensivos. A insignificância estatística e a inconsistência do sinal de FIRM sugerem que essa preocupação com o número absoluto de trabalhadores não ocorre na prática. Quanto à primeira hipótese, as transformações das últimas décadas na estrutura produtiva mundial não permitem descartá-la. Os países desenvolvidos - sobretudo os EUA - vêm se especializando na prestação de serviços e deixando a produção de muitos bens a cargo de outros países. ${ }^{18}$ Essa prestação de serviços é intensiva em "capital humano" mas não necessariamente nas formas de capital tradicionalmente mensuradas. Países como China e Índia, por outro lado, são abundantes em mão-de-obra e vêm se especializando nas atividades que utilizam intensivamente esse fator. Dessa forma, a vantagem comparativa do Brasil poderia estar se deslocando para os bens intensivos em capital físico - não pelo aumento relativo na oferta doméstica desse fator, mas pelo reposicionamento econômico dos EUA e da Ásia. ${ }^{19}$ Essa percepção é reforçada pelo fato de que os setores da economia brasileira que mais se queixam da competição chinesa não são os intensivos em capital, mas os intensivos em mão-de-obra, como têxteis e calçados. ${ }^{20}$ Portanto, a premissa de que o Brasil é intensivo em mão-de-obra (relativamente à média mundial) pode não mais se sustentar. $O$ sinal positivo de TRAB pode, dessa forma, refletir uma possível mudança na configuração produtiva mundial, com o Brasil perdendo competitividade em setores trabalho-intensivos e ganhando competitividade em setores capital-intensivos.

De todas as variáveis explanatórias, FIRM é a que apresenta pior desempenho nos testes empíricos. Embora tenha apresentado a mesma proporção de sinais positivos/negativos que TRAB, a distribuição desses sinais é errática: os sinais são diferentes, por exemplo, em ALC1 e ALC2, embora essas duas variáveis representem um mesmo contexto institucional (a formulação da oferta do Mercosul na ALCA). Em cada "dupla" de variáveis - ALC1/ALC2, UE1A/UE1B, UE4A/UE4B - o sinal de TRAB se mantém o mesmo (positivo ou negativo para ambas as variáveis), enquanto o sinal de FIRM se altera (positivo para uma variável e negativo para a outra). Ademais, FIRM só aparece como estatisticamente significativa em um único modelo (UE4A). A razão para esse fraco desempenho pode ser que um maior número de firmas, embora implique maiores custos de ação coletiva, também implica mais recursos para a prática de lobby - e em tal magnitude que ambos os efeitos se anulam.

Em resumo, apurou-se que o nível de proteção: (i) correlaciona-se positivamente com o grau de concentração econômica e com a trabalho-intensividade; (ii) correlaciona-se negativamente com o grau de instrução dos trabalhadores; e (iii) não se correlaciona com o número de firmas. A comparabilidade desses resultados com as demais aplicações da TPE ao caso brasileiro é limitada, pois o conjunto de variáveis é diferente e as variáveis que teoricamente são as mesmas têm formas de construção distintas. Não obstante, pode-se dizer que os resultados descritos acima são consistentes com o encontrado em trabalhos anteriores. Olarreaga e Soloaga (1998) regridem a TEC média (ponderada pelas importações)

\footnotetext{
${ }^{18}$ Segundo Baumol (2002, p.2), no ano 2000 mais de $60 \%$ da força de trabalho dos EUA estava empregada no chamado "setor de informação" e menos de $20 \%$ nos setores de manufatura e agricultura.

${ }^{19}$ É importante lembrar que a abundância de fatores não é um dado absoluto, mas relativo à proporção de cada fator na economia doméstica e na economia mundial. Logo, as vantagens comparativas do país podem se transformar mesmo que sua oferta doméstica de fatores continue a mesma.

${ }^{20}$ O setor têxtil foi objeto de acordo de restrição voluntária das exportações entre o Brasil e a China, em fevereiro de 2006 . Os calçados, embora tenham uma TEC de $20 \%$, estão na Lista de Exceções do Brasil com alíquota elevada a $35 \%$ (que é a tarifa máxima que o Brasil pode aplicar a esses produtos, dados os tetos tarifários estabelecidos na Rodada Uruguai).
} 
a sete variáveis independentes, das quais três mostram-se estatisticamente significativas: trabalhointensividade, grau de concentração econômica e salário médio. As duas primeiras variáveis apresentam sinal positivo e a terceira, sinal negativo. Esse resultado é bastante semelhante ao encontrado nas Tabelas 3 e 4, acima: significância estatística para as variáveis CONC, TRAB e INST, as duas primeiras com sinal positivo e a última - que guarda forte correlação com o salário médio - com sinal negativo. Não obstante, cabe ressaltar as seguintes diferenças entre ambos os trabalhos: (i) os contextos institucionais analisados são distintos (Olarreaga e Soloaga (1998), não analisam ofertas do Mercosul em negociações externas, enquanto o presente estudo não analisa restrições ao comércio intra-bloco); (ii) Olarreaga e Soloaga (1998) tomam como variável dependente a TEC média ponderada pelo valor das importações, a despeito dos problemas discutidos em 3.1 (a média ponderada subestima a proteção dos setores com tarifas muito altas e superestima a proteção dos setores com tarifas muito baixas); (iii) Olarreaga e Soloaga (1998) calculam o grau de concentração como [(número de empresas em toda a economia) / (número de empresas do setor)], o que não pode ser considerado como uma medida de concentração; ${ }^{21}$ e (iv) Olarreaga e Soloaga (1998) incluem em sua especificação regressores significativamente afetados pela estrutura de proteção vigente, como a penetração das importações e o nível de comércio intra-firma. ${ }^{22}$

\section{CONCLUSÃO}

Os resultados das regressões não são suficientes para se afirmar que os lobbies protecionistas são o principal determinante da estrutura de proteção comercial do Brasil. Dos quatro regressores utilizados, apenas o grau de concentração econômica (CONC) apresentou o sinal esperado de forma consistente (i.e., em uma proporção razoável dos modelos e com significância estatística). A quantidade de firmas (FIRM) apresentou sinal errático e não-significativo. A trabalho-intensividade (TRAB) tem, na maioria dos modelos, sinal oposto ao esperado e em apenas duas regressões seu coeficiente é estatisticamente significativo. Aventou-se uma explicação para esse sinal que é compatível com a TPE mas, naturalmente, trata-se de explicação ad hoc. O grau de instrução dos trabalhadores (INST) tem sinal oposto ao esperado em todas as regressões e coeficiente estatisticamente significativo em 3/4 dessas regressões. A explicação que se aventou para o sinal observado de INST é que o governo concede proteção antes por motivações sociais do que em função da maior ou menor demanda de proteção por cada setor da economia. Essa explicação, como é fácil perceber, contraria a própria essência da TPE: se os formuladores da política comercial gozam de algum grau de autonomia e portanto agem com outros objetivos além da obtenção/manutenção do poder político, e se esses outros objetivos são fundamentais na formulação da política comercial, então é necessário discutir-se a validade de uma teoria que, em sua essência, postula que toda proteção é endógena.

\section{Referências Bibliográficas}

Balassa, B. (1971). The Structure of Protection in Developing Countries. J. Hopkins, Baltimore.

Baumol, W. J. (2002). The Free Market Innovation Machine: Analyzing the Growth Miracle of Capitalism. Princeton University Press, Princeton.

Brock, W. A. \& Magee, S. P. (1978). The economics of special interest politics: The case of the tariff. The American Economic Review, 68(2):246-250.

21 "The concentration ratio shows the percentage of market sales accounted for by, for example, the largest four firms or the largest eight firms." Pass et alii (2000, p. 88).

${ }^{22}$ Os autores reconhecem o problema mas limitam-se a esclarecer que "[...] due to data restrictions, the empirical section does not deal with endogeneity problems." Olarreaga e Soloaga (1998, p. 317). 
Caves, R. E. (1976). Economic models of political choice: Canada's tariff structure. The Canadian Journal of Economics, 9(2):278-300.

Ehrlich, S. (2005). How common is the common external tariff? Domestic influences on European Union trade policy. In Annual Meeting of the American and Midwest Political Science Association. Midwest Political Science Association, Chicago. Disponível em http://mailer.fsu .edu/ sehrlich/papers/ CET.pdf. Acesso em 12 mai 2008.

Gawande, K. \& Bandyopadhyay, U. (2000). Is protection for sale? Evidence on the Grossman-Helpman theory of endogenous protection. The Review of Economics and Statistics, 82(1):139-152.

Gawande, K. \& Krishna, P. (2003). The political economy of trade policy: Empirical approaches. In Choi, E. \& Harrigan, J., editors, Handbook of International Trade, chapter 8. Blackwell, Malden.

Gawande, K., Sanguinetti, P., \& Bohara, A. (2001). Exclusions for sale: Evidence on the GrossmanHelpman model of free-trade agreements. Technical Report 4, Albuquerque: Nafta-Mercosur.

Goldberg, P. K. \& Maggi, G. (1999). Protection for sale: An empirical investigation. The American Economic Review, 8(5):1135-1155.

Grether, J. M., de Melo, J., \& Olarreaga, M. (1999). Who determines Mexican trade policy? Technical Report 2176, London: CEPR.

Grossman, G. M. \& Helpman, E. (1994). Protection for sale. The American Economic Review, 4(4):833-850.

Gujarati, D. N. (2006). Econometria Básica. Elsevier, Rio de Janeiro, 4 edition.

Hall, H. L., Finger, J. M., \& Nelson, D. R. (1982). The political economy of administered protection. The American Economic Review, 72(3):452-466.

Imai, S., Katayama, H., \& Krishna, K. (2008). A quantile-based test of protection for sale model. Technical Report 13900, Cambridge: NBER.

Mayer, W. (1984). Endogenous tariff formation. The American Economic Review, 74(5):970-985.

Mendenhall, W. \& Sicinch, T. (2003). A Second Course in Statistics: Regression Analysis. Prentice Hall, New York.

Nordlinger, E. A. (1981). On the Autonomy of the Democratic State. Harvard University Press, Cambridge.

Olarreaga, M. \& Soloaga, I. (1998). Endogenous tariff formation: The case of Mercosur. World Bank Economic Review, 12(2):297-320.

Olson, M. (1971). The Logic of Collective Action: Public Goods and the Theory of Groups. Harvard University Press, Cambridge, 2nd edition.

Pass, C., Lowes, B., \& Davies, S. (2001). Collins Dictionary of Economics. Collins, New York, 3rd edition.

Ray, E. J. (1981a). The determinants of tariff and nontariff trade restrictions in the United States. The Journal of Political Economy, 89(1):105-121.

Ray, E. J. (1981b). Tariff and nontariff barriers to trade in the United States and abroad. The Review of Economics and Statistics, 63(2):161-168.

Ray, E. J. \& Marvel, H. P. (1983). The Kennedy Round: Evidence on the regulation of international trade in the United States. The American Economic Review, 73(1):190-197. 
Ray, E. J. \& Marvel, H. P. (1984). The pattern of protection in the industrializaed world. The Review of Economics and Statistics, 66(3):452-486.

Saunders, R. S. (1980). The political economy of effective tariff protection in Canada's manufacturing sector. The Canadian Journal of Economics, 13(2):340-348.

Trefler, D. (1993). Trade liberalization and the theory of endogenous protection: An econometric study of U.S. import policy. The Journal of Political Economy, 101(1):138-160. 


\section{A. APÊNDICE}

Tabela 5: Exclusões por Capítulo da NCM

\begin{tabular}{|c|c|c|}
\hline Capítulo & Descrição & \% de itens excluídos \\
\hline 1 & Animais vivos & 48,00 \\
\hline 2 & Carnes e miudezas, comestíveis & 72,58 \\
\hline 3 & Peixes e crustáceos, moluscos e os outros invertebrados aquáticos & 53,00 \\
\hline 4 & $\begin{array}{l}\text { Leite e laticínios; ovos de aves; mel natural; produtos comestíveis de origem animal, } \\
\text { não especificados nem compreendidos em outros Capítulos }\end{array}$ & 58,14 \\
\hline 5 & $\begin{array}{l}\text { Outros produtos de origem animal, não especificados nem compreendidos em outros } \\
\text { Capitulos }\end{array}$ & 24,14 \\
\hline 6 & Plantas vivas e produtos de floricultura & 10,53 \\
\hline 7 & Produtos hortícolas, plantas, raízes e tubérculos, comestíveis & 32,05 \\
\hline 8 & Frutas; cascas de cítricos e de melões & 56,45 \\
\hline 9 & Café, chá, mate e especiarias & 17,14 \\
\hline 10 & Cereais & 25,71 \\
\hline 11 & Produtos da indústria de moagem; malte; amidos e féculas; inulina; glutén de trigo & 45,95 \\
\hline 12 & $\begin{array}{l}\text { Sementes e frutos oleaginosos; grãos, sementes e frutos diversos; plantas industriais } \\
\text { ou medicinais; palhas e forragens }\end{array}$ & 27,42 \\
\hline 13 & Gomas, resinas e outros sucos e extratos vegetais & 30,43 \\
\hline 14 & $\begin{array}{l}\text { Matérias para entrançar e outros produtos de origem vegetal, não especificados nem } \\
\text { compreendidos em outros Capítulos }\end{array}$ & 54,55 \\
\hline 15 & $\begin{array}{l}\text { Gorduras e óleos animais ou vegetais; produtos da sua dissociação; gorduras alimenta- } \\
\text { res elaboradas; ceras de origem animal ou vegetal }\end{array}$ & 37,68 \\
\hline 16 & $\begin{array}{l}\text { Preparações de carne, de peixes ou de crustáceos, de moluscos ou de outros inverte- } \\
\text { brados aquáticos }\end{array}$ & 87,50 \\
\hline 17 & Açúcares e produtos de confeitaria & 95,45 \\
\hline 18 & Cacau e suas preparações & 84,62 \\
\hline 19 & $\begin{array}{l}\text { Preparações à base de cereais, farinhas, amidos, féculas ou de leite; produtos de paste- } \\
\text { laria }\end{array}$ & 88,46 \\
\hline 20 & Preparações de produtos hortícolas, de frutas ou de outras partes de plantas & 100,00 \\
\hline 21 & Preparações alimentícias diversas & 97,37 \\
\hline 22 & Bebidas, líquidos alcoólicos e vinagres & 66,67 \\
\hline 23 & Resíduos e desperdícios das indústrias alimentares; alimentos preparados para animais & 51,43 \\
\hline 24 & Fumo (tabaco) e seus sucedâneos manufaturados & 33,33 \\
\hline 25 & Sal; enxofre; terras e pedras; gesso, cal e cimento & 92,63 \\
\hline 26 & Minérios, escórias e cinzas & 100,00 \\
\hline 27 & $\begin{array}{l}\text { Combustíveis minerais, óleos minerais e produtos da sua destilação; matérias betumi- } \\
\text { nosas; ceras minerais }\end{array}$ & 6,25 \\
\hline 28 & $\begin{array}{l}\text { Produtos químicos inorgânicos; compostos inorgânicos ou orgânicos de metais precio- } \\
\text { sos, de elementos radioativos, de metais das terras raras ou de isótopos }\end{array}$ & 11,22 \\
\hline 29 & Produtos químicos orgânicos & 32,83 \\
\hline 30 & Produtos farmacêuticos & 83,15 \\
\hline 31 & Adubos ou fertilizantes & 37,50 \\
\hline 32 & $\begin{array}{l}\text { Extratos tanantes e tintoriais; taninos e seus derivados; pigmentos e ou tras matérias } \\
\text { corantes; tintas e vernizes; mástiques; tintas de escrever }\end{array}$ & 30,69 \\
\hline 33 & $\begin{array}{l}\text { Óleos essenciais e resinóides; produtos de perfumaria ou de toucador preparados e } \\
\text { preparações comésticas }\end{array}$ & 41,07 \\
\hline 34 & $\begin{array}{l}\text { Sabões, agentes orgânicos de superficie, preparações para lavagem, preparações lubri- } \\
\text { ficantes, ceras artificiais, ceras preparadas, produtos de conservação e limpeza, velas e } \\
\text { artigos semelhantes, massas ou pastas para modelar, "ceras"para dentistas e composi- } \\
\text { ções para dentistas à base de gesso }\end{array}$ & 48,94 \\
\hline 35 & $\begin{array}{l}\text { Matérias albuminóides; produtos à base de amidos ou de féculas modificados; colas; } \\
\text { enzimas }\end{array}$ & 30,77 \\
\hline 36 & $\begin{array}{l}\text { Pólvoras e explosivos; artigos pirotecnia; fósforos; ligas pirofóricas; matérias inflamá- } \\
\text { veis }\end{array}$ & 0,00 \\
\hline 37 & Produtos para fotografia e cinematografia & 80,60 \\
\hline 38 & Produtos diversos das indústrias químicas & 32,51 \\
\hline 39 & Plásticos e suas obras & 58,48 \\
\hline 40 & Borracha e suas obras & 67,65 \\
\hline 41 & Peles, exceto a peleteria (peles com pêlo), e couros & 50,79 \\
\hline 42 & $\begin{array}{l}\text { Obras de couro; artigos de correeiro ou de seleiro; artigos de viagem, bolsas e artefatos } \\
\text { semelhantes; obras de tripa }\end{array}$ & 100,00 \\
\hline 43 & Peleteria (peles com pêlo) e suas obras; peleteria (peles com pêlo) artificial & 100,00 \\
\hline 44 & Madeira, carvão vegetal e obras de madeira & 100,00 \\
\hline
\end{tabular}


Tabela 5: Exclusões por Capítulo da NCM (continuação)

\begin{tabular}{|c|c|c|}
\hline Capítulo & Descrição & \% de itens excluídos \\
\hline 45 & Cortiça e suas obras & 100,00 \\
\hline 46 & Obras de espartaria ou de cestaria & 100,00 \\
\hline 47 & $\begin{array}{l}\text { Pastas de madeira ou de matérias fibrosas celulósicas; papel ou cartão de reciclar (des- } \\
\text { perdícios e aparas) }\end{array}$ & 100,00 \\
\hline 48 & Papel e cartão; obras de pasta de celulose, de papel ou de cartão & 99,28 \\
\hline 49 & $\begin{array}{l}\text { Livros, jornais, gravuras e outros produtos das indústrias gráficas; textos manuscritos } \\
\text { ou datilografados, planos e plantas }\end{array}$ & 47,83 \\
\hline 50 & Seda & 100,00 \\
\hline 51 & Lã, pelos finos ou grosseiros; fios e tecidos de crina & 100,00 \\
\hline 52 & Algodão & 100,00 \\
\hline 53 & Outras fibras têxteis vegetais; fios de papel e tecidos de fios de papel & 100,00 \\
\hline 54 & Filamentos sintéticos ou artificiais & 100,00 \\
\hline 55 & Fibras sintéticas ou artificiais, descontínuas & 100,00 \\
\hline 56 & $\begin{array}{l}\text { Pastas ("ouates"), feltros e falsos tecidos; fios especiais; cordéis, cordas e cabos; artigos } \\
\text { de cordoaria }\end{array}$ & 100,00 \\
\hline 57 & Tapetes e outros revestimentos para pavimentos, de matérias têxteis & 100,00 \\
\hline 58 & Tecidos especiais; tecidos tufados; rendas; tapeçarias; passamanarias; bordados & 100,00 \\
\hline 59 & $\begin{array}{l}\text { Tecidos impregnados, revestidos, recobertos ou estratificados; artigos para usos técni- } \\
\text { cos de matérias têxteis }\end{array}$ & 100,00 \\
\hline 60 & Tecidos de malha & 100,00 \\
\hline 61 & Vestuário e seus acessórios, de malha & 100,00 \\
\hline 62 & Vesturário e seus acessórios, exceto de malha & 100,00 \\
\hline 63 & $\begin{array}{l}\text { Outros artefatos têxteis confeccionados; sortidos artefatos de matérias têxteis, calça- } \\
\text { dos, chapéus e artefatos de uso semelhante; usados; trapos }\end{array}$ & 100,00 \\
\hline 64 & Calçados, polainas e artefatos semelhantes, e suas partes & 100,00 \\
\hline 65 & Chapéus e artefatos de uso semelhante, e suas partes & 100,00 \\
\hline 66 & $\begin{array}{l}\text { Guarda-chuvas, sombrinhas, guarda-sóis, bengalas, bengalas-assentos, chicotes, reben- } \\
\text { ques e suas partes }\end{array}$ & 100,00 \\
\hline 67 & Penas e penugem preparadas, e suas obras; flores artificiais; obras de cabelo & 100,00 \\
\hline 68 & Obras de pedra, gesso, cimento, amianto, mica ou de matérias semelhantes & 100,00 \\
\hline 69 & Produtos cerâmicos & 94,83 \\
\hline 70 & Vidro e suas obras & 11,11 \\
\hline 71 & $\begin{array}{l}\text { Pérolas naturais ou cultivadas, pedras preciosas ou semipreciosas e semelhantes, me- } \\
\text { tais preciosos, metais folheados ou chapeados de metais preciosos, e suas obras; biju- } \\
\text { terias; moedas }\end{array}$ & 81,97 \\
\hline 72 & Ferro fundido, ferro e aço & 100,00 \\
\hline 73 & Obras de ferro fundido, ferro ou aço & 100,00 \\
\hline 74 & Cobre e suas obras & 98,67 \\
\hline 75 & Níquel e suas obras & 100,00 \\
\hline 76 & Alumínio e suas obras & 54,72 \\
\hline 78 & Chumbo e suas obras & 75,00 \\
\hline 79 & Zinco e suas obras & 66,67 \\
\hline 80 & Estanho e suas obras & 100,00 \\
\hline 81 & Outros metais comuns; ceramais ("cermets"); obras dessas matérias & 95,74 \\
\hline 82 & Ferramentas, artefatos de cutelaria e talheres, e suas partes, de metais comuns & 98,82 \\
\hline 83 & Obras diversas de metais comuns & 100,00 \\
\hline 84 & $\begin{array}{l}\text { Reatores nucleares, caldeiras, máquinas, aparelhos e instrumentos mecânicos, e suas } \\
\text { partes }\end{array}$ & 41,36 \\
\hline 85 & $\begin{array}{l}\text { Máquinas, aparelhos e materiais elétricos, e suas partes; aparelhos de gravação ou de } \\
\text { reprodução de som, aparelhos de gravação ou de reprodução de imagens e de som em } \\
\text { televisão, e suas partes e acessórios }\end{array}$ & 75,88 \\
\hline 86 & $\begin{array}{l}\text { Veículos e material para vias férreas ou semelhantes, e suas partes; aparelhos mecâni- } \\
\text { cos (incluídos os eletromecânicos) de sinalização para vias férreas de comunicação }\end{array}$ & 93,33 \\
\hline 87 & $\begin{array}{l}\text { Veículos automóveis, tratores, ciclos e outros veículos terrestres, suas partes e acessó- } \\
\text { rios }\end{array}$ & 92,37 \\
\hline 88 & Aeronaves e aparelhos espaciais, e suas partes & 12,00 \\
\hline 89 & Embarcações e estruturas flutuantes & 27,78 \\
\hline 90 & $\begin{array}{l}\text { Instrumentos e aparelhos de óptica, fotografia ou cinematografia, medida, controle ou } \\
\text { de precisão; instrumentos e aparelhos médico-cirúrgicos; suas partes e acessórios }\end{array}$ & 41,38 \\
\hline 91 & Aparelhos de relojoaria e suas partes & 100,00 \\
\hline 92 & Instrumentos musicais; suas partes e acessórios & 100,00 \\
\hline 93 & Armas e munições; suas partes e acessórios & 100,00 \\
\hline
\end{tabular}


Tabela 5: Exclusões por Capítulo da NCM (continuação)

\begin{tabular}{|c|l|c|}
\hline Capítulo & \multicolumn{1}{|c|}{ Descrição } & $\%$ de itens excluídos \\
\hline 94 & $\begin{array}{l}\text { Móveis; mobiliário médico-cirúrgico; colchões, almofadas e semelhantes; aparelhos de } \\
\text { iluminação não especificados nem compreendidos em outros Capítulos; anúncios, car- } \\
\text { tazes ou tabuletas e placas indicadoras luminosos, e artigos semelhantes; construções } \\
\text { pré-fabricadas }\end{array}$ & 92,31 \\
\hline 95 & Brinquedos, jogos, artigos para divertimento ou para esporte; suas partes e acessórios & 100,00 \\
\hline 96 & Obras diversas & 100,00 \\
\hline 97 & Objetos de arte, de coleção e antigüidades & 100,00 \\
\hline
\end{tabular}

